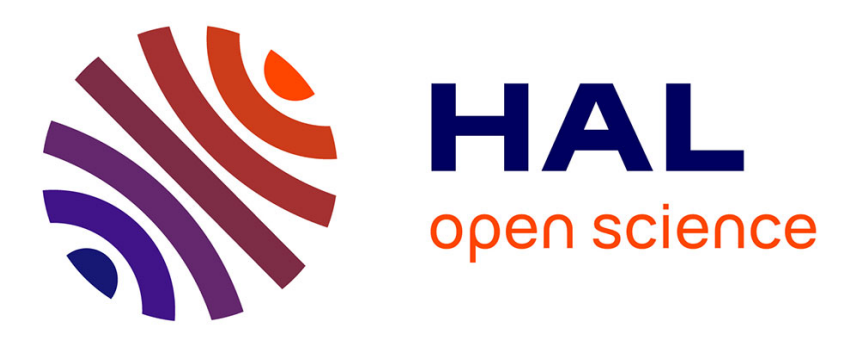

\title{
The German version of the Anorectic Behavior Observation Scale (ABOS)
}

Harriet Salbach-Andrae, Nora Klinkowski, Martin Holzhausen, Katja Frieler, Inga Bohnekamp, Cornelia Thiels, Caroline Bender, Walter Vandereycken

\section{- To cite this version:}

Harriet Salbach-Andrae, Nora Klinkowski, Martin Holzhausen, Katja Frieler, Inga Bohnekamp, et al. The German version of the Anorectic Behavior Observation Scale (ABOS). European Child and Adolescent Psychiatry, 2009, 18 (5), pp.321-325. 10.1007/s00787-008-0732-6 . hal-00486570

\author{
HAL Id: hal-00486570 \\ https://hal.science/hal-00486570
}

Submitted on 26 May 2010

HAL is a multi-disciplinary open access archive for the deposit and dissemination of scientific research documents, whether they are published or not. The documents may come from teaching and research institutions in France or abroad, or from public or private research centers.
L'archive ouverte pluridisciplinaire HAL, est destinée au dépôt et à la diffusion de documents scientifiques de niveau recherche, publiés ou non, émanant des établissements d'enseignement et de recherche français ou étrangers, des laboratoires publics ou privés. 
Harriet Salbach-Andrae

Nora Klinkowski

Martin Holzhausen

Katja Frieler

Inga Bohnekamp

Cornelia Thiels

Caroline Bender

Walter Vandereycken

\section{The German version of the Anorectic Behavior Observation Scale (ABOS)}

Received: 11 March 2008

Accepted: 23 September 2008

Published online: 22 January 2009

H. Salbach-Andrae $(\square) \cdot$ N. Klinkowski

I. Bohnekamp

Dept. of Child and Adolescent Psychiatry

Charité

Berlin, Germany

E-Mail: harriet.salbach@charite.de

\section{Holzhausen · K. Frieler}

Dept. of Biostatistics and Clinical

Epidemiology

Charité

Berlin, Germany

C. Thiels

Dept. of Social Studies

University of Applied Sciences

Bielefeld, Germany
Abstract Objective To assess the performance of the German version of the Anorectic Behavior Observation Scale (ABOS) as a parent-report screening instrument for eating disorders (ED) in their children. Methods Parents of $101 \mathrm{ED}$ female patients (80 with Anorexia Nervosa; 21 with Bulimia Nervosa) and of 121 age- and socioeconomic status (SES)-

\section{Bender}

Dept. of Psychology

University of Freiburg

Freiburg, Germany

W. Vandereycken

Dept. of Psychology

Catholic University Leuven

Leuven, Germany matched female controls completed the ABOS. Results Confirmatory factor analysis supported the original three-factor structure model of the ABOS. Cronbach's alpha coefficients indicated good internal consistency for the three factors and the total score in the total sample. The best cut-off point $(100 \%$ sensitivity and specificity) in the German version was $\geq 23$. Conclusion The ABOS may be a useful additional instrument for assessing ED.

Key words anorexia nervosa bulimia nervosa - questionnaire confirmatory factor analysis

\section{Introduction}

Various self-report instruments have been developed to assess symptoms related to eating disorders. The widely used Eating Attitudes Test (EAT-40: [11]; EAT26: [12]) and the Eating Disorder Inventory (EDI: [13]; EDI-2: [10]; EDI-3: [9]) for example, were designed to explore cognitive and behavioural symptoms of eating disorders (ED). These instruments provide information helpful in understanding the patient. As the psychopathology related to ED is very heterogeneous, such descriptive information is particularly relevant in individual cases.

Anorexia Nervosa (AN) can develop from about 8 years of age, reaching a peak between 15 and
18 years. Bulimia Nervosa $(\mathrm{BN})$ becomes more common in young adulthood [14]. Within these age-groups, gathering data from the patients' parents and including them in the treatment is very important, because patients suffering from ED often deny or minimize their own disorder $[4,15,16,18$, 20].

The Anorectic Behavior Observation Scale (ABOS) developed by Vandereycken and Meermann [19] assesses symptoms of patients suffering from AN and BN based on her or his parents' or carers' observations. The ABOS can be a useful instrument for the evaluation of the course of eating disorders, e.g. before and after treatment. Moreover, it can be applied for screening subjects in whom the eating disorder appears to be in an early stage. So far the ABOS has 
Table 1 Group means and standard deviations for demographic and BMI data

\begin{tabular}{|c|c|c|c|c|c|}
\hline Variable & $\mathrm{AN}-\mathrm{R}(n=63)$ & AN-BP $(n=17)$ & $\mathrm{BN}(n=21)$ & Healthy controls $(n=134)$ & ANOVA or $\chi^{2}$-test \\
\hline Age (years) ${ }^{\mathrm{a}}$ & $15.9 \pm 1.4$ & $16.5 \pm 1.4$ & $16.5 \pm 1.6$ & $16.2 \pm 0.8$ & $F=2.2, P=0.09$ \\
\hline SES: high ${ }^{\text {b }}$ & $19(30.2 \%)$ & $7(41.2 \%)$ & $2(9.5 \%)$ & $28(20.9 \%)$ & $\chi^{2}=9.8 ; \mathrm{df}=6, P=0.13$ \\
\hline SES: middle ${ }^{b}$ & $40(63.5 \%)$ & $8(47.1 \%)$ & $18(85.7 \%)$ & $100(74.6 \%)$ & \\
\hline SES: $\operatorname{low}_{\mathrm{b}}$ & $4(6.3 \%)$ & $2(11.8 \%)$ & $1(4.8 \%)$ & $6(4.5 \%)$ & \\
\hline BMI $\left(\mathrm{kg} / \mathrm{m}^{2}\right)^{\mathrm{a}}$ & $15.0 \pm 1.4$ & $16.0 \pm 0.7$ & $20.3 \pm 1.6$ & $20.1 \pm 1.7$ & $F=173.5, P<.001^{* * *}$ \\
\hline $\mathrm{ABOS}^{\mathrm{C}}$ & $35.94 \pm 4.35$ & $38.88 \pm 6.90$ & $34.24 \pm 5.54$ & $4.17 \pm 5.06$ & $F=758.4, P<0.001^{* * *}$ \\
\hline
\end{tabular}

SES socioeconomic status, $B M I\left(\mathrm{~kg} / \mathrm{m}^{2}\right)$ body mass index $\left(\mathrm{kg} / \mathrm{m}^{2}\right), A N-R$ Anorexia nervosa restricting type, $A N-B P$ anorexia nervosa bingeing/purging type, $B N$ bulimia nervosa

${ }^{\mathrm{a}}$ Mean $\pm \mathrm{SD}$

${ }^{\mathrm{b}}$ Absolute frequency (\%)

${ }^{\mathrm{A}} \mathrm{ABOS}$ total score

been used mainly in adolescents from the age of 12 years on. Vandereycken [18] confirmed the validity and reliability of the Dutch version of the ABOS, and Uehara et al. [17] approved its three-factor structure in a Japanese sample.

The aim of this study was (1) to confirm the threefactor structure of the ABOS using data from a German sample; and (2) to assess the validity and clinical usefulness of the German version of the ABOS in a clinical eating disorder sample.

\section{Method}

\section{Subjects}

Informed consent was obtained from the participants and their parents. The study was approved by the Institutional Review Board. We analysed the ABOSdata (German version) from 101 female ED in- and outpatients recruited from the Department of Child and Adolescent Psychiatry, Psychosomatics and Psychotherapy, Charité-Universitätsmedizin Berlin (Germany). Sixty-three patients suffered from AN restricting subtype (ANR), 17 from AN binge-purge subtype (ANBP), and 21 from BN. All ED patients met the DSM-IV criteria for ED [2] and were aged between 12 and 18 years. AN was diagnosed by a structured interview (SIAB; [6-8]) that assesses the prevalence and severity of specific eating-related pathology over the past 3 months according to DSM-IV diagnostic criteria for people aged between 12 and 65 years. Inter-rater reliability of the SIAB is high, Cronbach's alpha coefficients range between 0.43 and 0.91 [8]. Clinically experienced and trained research assistants under the supervision of the attending child and adolescent psychiatrist conducted the interviews. Two patients had to be excluded due to missing ABOS data. Patients suffering from $\mathrm{ED}$ other than $\mathrm{AN}$ and $\mathrm{BN}$ were not included in the study. All parents knew about the diagnoses of their child. Socioeconomic status (SES) was measured on an eleven-point scale assessing the parents' self-reported occupational status [5]. The scale places each occupation into one of eleven categories ( 1 = unskilled laborer, $6=$ professional employed, $7=$ unskilled self-employed, $11=$ professional selfemployed). We distinguished three SES groups: High (groups 5, 6, 10, 11; e.g., manager, physician), middle (groups 3, 4, 9; e.g., electrician, nurse) and low (groups 1, 2, 7, 8; e.g., cashier, textile machine operator).

Furthermore, the questionnaire was administered to 134 female controls matched for age and SES drawn from German high schools. Total body height (in $\mathrm{cm}$ ) and body mass (in $\mathrm{kg}$ ) were measured using standard techniques, and Body Mass Index (BMI) was calculated. Control subjects with BMI $<18$ and $>24$ or Tscores above 59 on the two broadband scales and the total problem scale of the child behavior checklist (CBCL) were excluded from the study [1]. Sixteen participants had to be excluded due to missing CBCL or ABOS values, and also due to T-scores above 59 on the subscales or on the total problem scale of the CBCL. Table 1 shows the sociodemographic characteristics of all subjects.

\section{Measurement}

\section{ABOS}

The ABOS, originally developed by Vandereycken and Meermann [19], evaluates a patient's eating behaviour based on information obtained by his or her relatives. It consists of 30 dichotomous items to be answered with 'yes' ( 2 points) or 'no' ( 0 points) if relatives are certain, and '?' ( 1 point) if relatives are doubtful about the answer. The higher the total score, the more pathological the subject is regarded (highest score possible $=60$ ). Relatives should base their ratings of the 30 items on observations of the patient during the past month at home. The reliability and validity of the ABOS have been confirmed by Vandereycken [18]. The original version showed 
Table 2 Item examples of the ABOS

\begin{tabular}{|c|c|c|}
\hline Item & Factor & Wording \\
\hline 2 & I & Shows anger or hostility at mealtimes \\
\hline 6 & i & Exhibits unusual food faddism \\
\hline 9 & I & Prefers diet products \\
\hline 12 & $\|$ & Vomits after meals \\
\hline 18 & $\|$ & $\begin{array}{l}\text { Has sometimes difficulties in stopping eating } \\
\text { or eats unusually large amounts of food or sweets }\end{array}$ \\
\hline 19 & II & Complains a lot about constipation \\
\hline 20 & $\|$ & Frequently takes laxatives (purgatives) or asks for them \\
\hline 21 & I & Claims to be too fat (regardless of weight loss) \\
\hline 22 & I & $\begin{array}{l}\text { Often speaks about slimming, dieting or ideal body } \\
\text { forms }\end{array}$ \\
\hline 24 & III & Stands, walks or runs about whenever possible \\
\hline 26 & III & Does a lot of physical exercise or sports \\
\hline
\end{tabular}

a three-factor structure: Factor I-eating behaviour, concern with weight and food, denial of problems (16 items: 1-7, 9, 10, 13, 14, 17, 21, 22, 29, 30); Factor II-bulimic-like behaviour (7 items: 8 (negative load), 12, 15, 16, 18, 19, 20); Factor III-hyperactivity (7 items: 11, 23, 24, 25, 26, 27, 28). For the German version, ABOS-items were first translated into German by an independent translator. To assure adequate item-wordings in the German version, the German text was then translated back to English by a second independent translator. The two English versions (original and back-translation) were regarded as similar enough to accept the German translation by an English native speaker. Table 2 presents item examples of the ABOS.

\section{Statistical analysis}

Two analyses were conducted to evaluate the theoretical structure (i.e., three factors) of the scale: First, internal consistency was assessed using Cronbach's alpha. Second, confirmatory factor analysis was conducted to test whether our data fitted the original three-factor model proposed by Vandereycken [18] using the analysis of moment structure (AMOS) version 4 statistical software package. Chi-square values to degrees of freedom ratios (CMIN/df), root mean square residual (RMR), goodness of fit index (GFI), adjusted GFI (AGFI), were calculated as the respective standardised goodness of fit indices in the confirmatory model. The following criteria were used to indicate an appropriate fit of the model with the present data: CMIN/df < 2.0; GFI > 0.9; AGFI > 0.9; $\mathrm{RMR}<0.08$. Also, the receiver operating characteristics (ROC) curve of the ABOS was calculated to assess the discriminant capacity of the questionnaire; sensitivity, specificity, positive predictive value (PPV) and negative predictive value (NPV) were specified.
Table 3 Reliability (cronbach's alpha) of the ABOS

\begin{tabular}{llll}
\hline & Whole sample & Eating disorder & Healthy controls \\
\hline Total score & 0.95 & 0.52 & 0.76 \\
Factor I & 0.94 & 0.53 & 0.67 \\
Factor II & 0.75 & 0.57 & 0.42 \\
Factor III & 0.87 & 0.67 & 0.51 \\
\hline
\end{tabular}

Table 4 Goodness-of-fit for the three-factor model in German, Belgian and Japanese samples

\begin{tabular}{lllll}
\hline Factor model & CMIN & GFI & AGFI & RMR \\
\hline Present study (Germany) & 1.78 & 0.70 & 0.66 & 0.08 \\
Original Belgian study (16) & 2.38 & 0.72 & 0.68 & 0.02 \\
Japanese Study (15) & 1.55 & 0.84 & 0.80 & 0.08 \\
\hline
\end{tabular}

CMIN/df Chi-square values to degrees of freedom ratios, GFI goodness of fit index, $A G F I$ adjusted GFI, RMR root mean square residual

\section{Results}

\section{Descriptives and group comparisons}

Table 1 shows sociodemographic characteristics, body mass indexes $\left(\mathrm{BMI}\left(\mathrm{kg} / \mathrm{m}^{2}\right)\right)$ and $\mathrm{ABOS}$ total score in the four groups. There were no significant differences regarding age and SES. As expected, there was a statistically significant difference in mean BMI $\left(\mathrm{kg} / \mathrm{m}^{2}\right)$. Scheffé post-hoc comparisons showed a significant lower BMI $\left(\mathrm{kg} / \mathrm{m}^{2}\right)$ in ANR patients than ANBP patients $(P<0.05)$, BN patients $(P<0.001)$, and healthy controls $(P<0.001)$. Furthermore, ANBP patients had a significant lower BMI $\left(\mathrm{kg} / \mathrm{m}^{2}\right)$ than BN patients $(P<0.001)$ and normal controls $(P<0.001)$. No significant differences in BMI $\left(\mathrm{kg} / \mathrm{m}^{2}\right)$ were found between $\mathrm{BN}$ patients and healthy controls $(P=0.99)$.

\section{Reliability (internal consistency)}

Cronbach's alpha was used to evaluate the reliability of the German version of the ABOS. Internal consistencies of the three factors and the total score were high for the entire sample, but much lower for the two subsamples (see Table 3 ).

\section{Confirmatory factor analysis (CFA)}

Comparisons of the goodness-of-fit indices between the original Belgian model, the Japanese and the German model are shown in Table 4 . The original three-factor model [18] fits our data relatively well as indicated by CMIN/df, GFI, AGFI, and RMR. Inter- 
Table 5 Sensitivity, specificity, positive and negative predictive values for ABOS

\begin{tabular}{lllll}
\hline Cut-off & Sensitivity & Specificity & $\begin{array}{l}\text { Positive predictive } \\
\text { value }\end{array}$ & $\begin{array}{l}\text { Negative predictive } \\
\text { value }\end{array}$ \\
\hline$\geq 5$ & 1 & 0.65 & 0.74 & 1 \\
$\geq 10$ & 1 & 0.83 & 0.85 & 1 \\
$\geq 19$ & 1 & 0.99 & 0.98 & 1 \\
$\geq 20$ & 1 & 0.99 & 0.99 & 1 \\
$\geq 23$ & 1 & 1 & 1 & 1 \\
\hline
\end{tabular}

ested readers can contact the authors for original CFA data. The global indices of goodness of fit derived from the original study [18] showed an equally low or slightly lower fit on GFI, AGFI, and CMIN/df. RMR was the only parameter that indicated a better fit in the original Belgian data than in the present study. In the Japanese study [17] slightly better or equal fit on GFI, AGFI, CMIN/df and RMR were found.

\section{Sensitivity, specificity, PPV and NPV}

In our sample a score of $\geq 23$ as cut-off yielded the best sensitivity and specificity possible. Table 5 summarizes sensitivity, specificity, PPV and NPV of the ABOS questionnaire for the detection of ED. The ROC curve is presented in Fig. 1.

\section{Discussion}

According to our findings, the ABOS can be used as a valid and reliable screening tool for ED in adolescents (in addition to existing self-report instruments). Confirmatory factor analysis using data from a German sample gives support for the three-factor structure proposed in the original Belgian study [18]. It was found that the internal consistency of the 30-item instrument was high for the total sample. However, reliability for the two subsamples was much lower; a fact that can largely be explained by the massively decreased intragroup variance in the subsamples compared to the total sample [3]. Reliability of the German ABOS clearly needs closer scrutiny in a

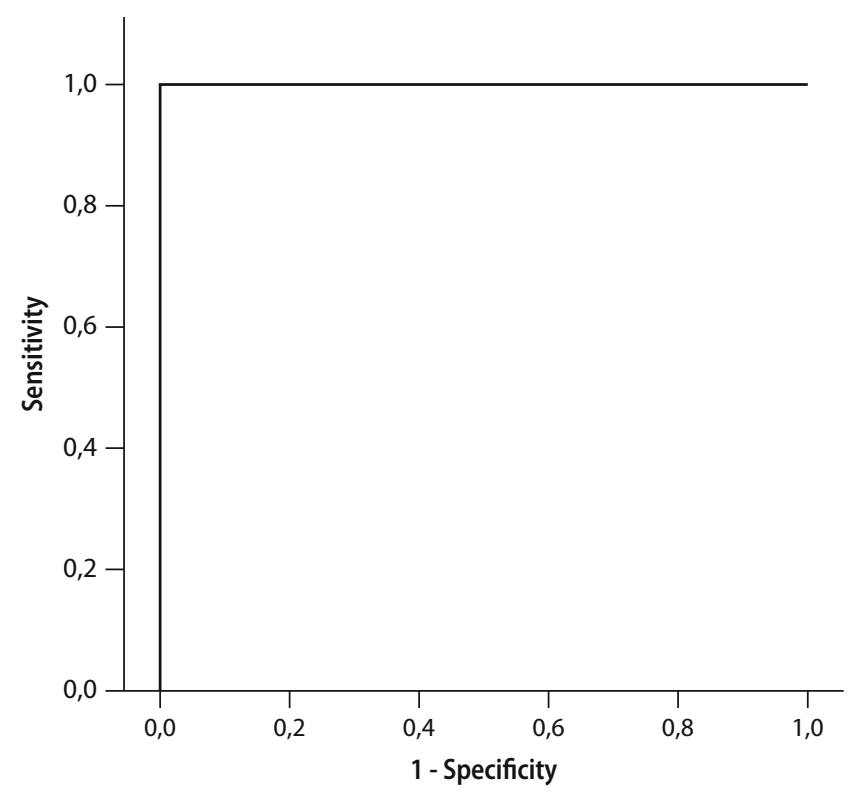

Fig. 1 ROC curve for ABOS

population-based sample (see below). Using a total cut-off score of $\geq 23$, the ABOS offered excellent levels of sensitivity and specificity. A limitation of this study is that based on the current sample (a clinical ED subsample and a non-clinical school-based sample), it is not possible to derive a cut-off score that would be appropriate for early identification of $\mathrm{ED}$ in the population that likely come with lower ABOS scores. Rather, the cut-off score $\geq 23$ informs about the test value that best discriminates girls that already have an ED in need for treatment from a school-based sample of girls. Future studies should examine, whether these levels of sensitivity, specificity, and predictive values can be replicated when screening for ED cases within the population.

In conclusion, the German version of the ABOS could be particularly useful in the early stages of an $\mathrm{ED}$, when patients show a tendency to deny or minimize their problems [20]. The parents' viewpoint seems to be a valuable source of information for both the assessment and treatment of ED in children and adolescents.

\section{References}

1. Achenbach TM (1991) Manual for the child behavior checklist/4-18 and 1991 profile. University of Vermont, Department of Psychiatry, Burlington
2. American Psychiatric Association (1994) Diagnostic and statistical manual of mental disorders (DSM-IV). American Psychiatric Press, Washington, DC
3. Bortz JND (2006) Forschungsmethoden und Evaluation: für Human- und Sozialwissenschaftler. Springer, Berlin 
4. Comer JS, Kendall PC (2004) A symptom-level examination of parent-child agreement in the diagnosis of anxious youths. J Am Acad Child Adolesc Psychiatry 43:878-886

5. Englert E, Poustka F (1995) The Frankfurt child and adolescent psychiatry documentation system-development and methodological principles with reference to quality assurance. Prax Kinderpsychol Kinderpsychiatr 44:158-167

6. Fichter MQN (1999) Strukturiertes Inventar für Anorektische und Bulimische Essstörungen nach DSM-IV und ICD-10. Hogrefe, Göttingen

7. Fichter M, Quadflieg N (2001) The structured interview for anorexic and bulimic disorders for DSM-IV and ICD-10 (SIAB-EX): reliability and validity. Eur Psychiatry 16:38-48

8. Fichter MM, Herpertz S, Quadflieg N, Herpertz-Dahlmann B (1998) Structured interview for anorexic and bulimic disorders for DSM-IV and ICD10: updated (third) revision. Int J Eat Disord 24:227-249
9. Garner DM (2004) The eating disorder inventory-3 (EDI-3): professional manual. Psychological Assessment Resources, Odessa

10. Garner DM (1991) Eating disorder inventory-2 professional manual. Psychological Assessment Resources, Odessa

11. Garner DM, Garfinkel PE (1979) The eating attitudes test: an index of the symptoms of anorexia nervosa. Psychol Med 9:273-279

12. Garner DM, Olmsted MP, Bohr Y, Garfinkel PE (1982) The eating attitudes test: psychometric features and clinical correlates. Psychol Med 12:871-878

13. Garner DM, Olmsted MP (1984) The eating disorders inventory manual. Psychological Assessment Resources, Odessa

14. Gowers SG (2008) Management of eating disorders in children and adolescents. Arch Dis Child 93:331-334

15. le Grange D, Crosby RD, Rathouz PJ, Leventhal BL (2007) A randomized controlled comparison of family-based treatment and supportive psychotherapy for adolescent bulimia nervosa. Arch Gen Psychiatry 64:1049-1056
16. Lock J, Agras WS, Bryson S, Kraemer HC (2005) A comparison of short- and long-term family therapy for adolescent anorexia nervosa. J Am Acad Child Adolesc Psychiatry 44:632-639

17. Uehara T, Takeuchi K, Ohmori I, Kawashima Y, Goto M, Mikuni M, Vandereycken W (2002) Factor-analytic study of the anorectic behavior observation scale in Japan: comparisons with the original Belgian study. Psychiatry Res 111:241-246

18. Vandereycken W (1992) Validity and reliability of the anorectic behavior observation scale for parents. Acta Psychiatr Scand 85:163-166

19. Vandereycken W, Meermann R (1984) Anorexia Nervosa: a clinician's guide to treatment. Walter de Gruyter, Berlin

20. Viglione V, Muratori F, Maestro S, Brunori E, Picchi L (2006) Denial of symptoms and psychopathology in adolescent anorexia nervosa. Psychopathology 39:255-260 